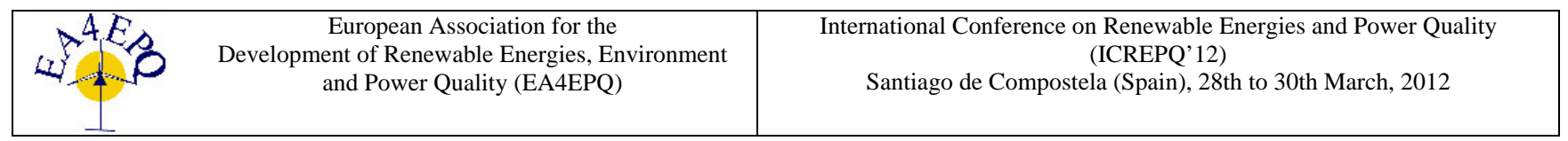

\title{
Minimalistic approach of a complex and flexible teaching laboratory for photovoltaic energy conversion: experience from courses at the Kasetsart University in Bangkok and at GPEsolar (Technical University Berlin)
}

\author{
Th. Dittrich \\ Helmholtz Center Berlin for Materials and Energy \\ Hahn-Meitner-Platz 1, 14109 Berlin \\ Phone:+0049 30 806242090, e-mail: dittrich@helmholtz-berlin.de
}

\begin{abstract}
A complex of more than ten laboratory tasks was developed complementary to lectures and seminars for teaching of principles of solar cells and their applications. The laboratory covers topics of basic characteristics, materials and types of solar cells as well as of characterization methods and applications in solar energy conversion and can be extended to research aspects. Students with different background can independently discover a certain aspect in the field of photovoltaic energy conversion within four hours. Tasks can be easily applied at universities in developed and developing countries and most of them can be reproduced at low cost. The mobile laboratory can be setup in a short time and is well suitable for changing places of teaching. The vision to implement related laboratory tasks into experimental interdisciplinary teaching centers for renewable energy at universities has been drawn.
\end{abstract}

\section{Key words}

teaching, solar cells, photovoltaic energy conversion

\section{Introduction}

Education in the field of renewable energies is a key for sustainable development and production in the future. Education including knowledge about basic principles, specialization and formation of mind in the field of renewable energies is a challenge for universities in all countries independent of their financial and ranking status. Solar energy conversion with solar cells bears the highest potential for renewable energy supply and will provide a major part in the renewable energy mix already in the next decades. A tremendous amount of young people is keen for knowledge about solar energy conversion including research, engineering, production and socio-economic consequences and the universities are responsible for their efficient teaching. A very efficient component of learning is the independent discovery in experiments.

The experience with a complex and flexible teaching laboratory in the field of solar cells and aspects of their application will be summarized. The laboratory has been developed complementary to a lecture course covering principles of solar cells, types of solar cells, solar cell materials and aspects of energy storage. The laboratory tasks are divided into four blocks:

Block A: Basic characteristics of solar cells

Block B: Parameter dependencies of solar cells

Block C: Aspects of solar cell materials

Block D: Applications of solar energy conversion Most of the laboratory tasks were developed by the author within different activities including teaching at the Kasetsart University (two weeks courses, Bangkok, 2008, 2011) and at GPEsolar (courses during the winter semesters, Technical University Berlin, started in 2008). The laboratory is permanently developing and open for any new ideas, improvements and tasks.

\section{Demands to the laboratory}

The following demands were considered during the development of the laboratory tasks:

(i) Students with different background should be able to perform a given task within four hours including reading of the manual, measurements, documentation and analysis of the results. The manuals should be as compact as possible and not extend about 4 pages for one laboratory task. This condition allows the implementation of the laboratory tasks also into activities limited in time such as summer schools with participants from different faculties and countries.

(ii) Advanced students can find the opportunity to extend their activities depending on progress in a given running laboratory task. This condition supports the creativity of students.

(iii) The students get the opportunity to work in little groups. This condition will develop the ability of students for team work.

(iv) Students become familiar with different types of solar cells, measurement equipment and methods, principles and loss mechanisms in solar cells, aspects of application of solar energy conversion, energy storage and selected research topics. This condition helps the student to 
broaden and to deepen knowledge in a given direction and to wake special interests.

(v) Students communicate their results about one given laboratory task at a lab conference. This condition gives the opportunity for discussions, drawing conclusions and for learning about experiments which were not carried out by all groups (each group performs usually 8 laboratory tasks within one course). Further the lab conference can help to improve presentation skills of students.

(vi) Each laboratory task reflects at least one basic principle or idea in a minimalistic approach excluding complicated facilities and keeping experiments as simple as needed.

(vii) The equipment is desirable light weight and mobile so that it can be taken to different universities in different countries.

(viii) Components of the equipment are desirable low cost so that they can be easily reproduced for teaching also in developing countries. This condition limits the dimension of solar cells to relatively small areas since high power demands more expensive equipment and additional safety measures.

(ix) A certain degree of improvisation should be kept for all laboratory tasks in order to avoid barriers often arising when people are faced with perfectionism.

\section{Content of laboratory tasks}

Table I gives the application scheme of the laboratory tasks the content of which will be briefly described in this section.

Table I. - Application scheme of the laboratory tasks during the two weeks courses at Kasetsart University Bangkok in 2008

(BA1) and 2011 (BA2) as well as during the winter semesters at GPEsolar in 2008/09 (GPE1), 2009/10 (GPE2), 2010/11 (GPE3) and 2011/12 (GPE4).

\begin{tabular}{|c|c|c|c|c|c|c|c|}
\hline & Task & BA & GPE & GPE & GPE & BA & GPE \\
\hline \multirow{5}{*}{$\mathrm{A}$} & A1 & & & & & & \\
\hline & A2 & & & & & & \\
\hline & A3 & & & & & & \\
\hline & A4 & & & & & & \\
\hline \multirow{5}{*}{$\mathrm{B}$} & B1 & & & & & & \\
\hline & B2 & & & & & & \\
\hline & B3 & & & & & & \\
\hline & B4 & & & & & & \\
\hline \multirow{5}{*}{ C } & C1 & & & & & & \\
\hline & C2 & & & & & & \\
\hline & C3 & & & & & & \\
\hline & C4 & & & & & & \\
\hline \multirow{2}{*}{$\mathrm{D}$} & D1 & & & & & & \\
\hline & D2 & & & & & & \\
\hline & D3 & & & & & & \\
\hline & D4 & & & & & & \\
\hline
\end{tabular}

\subsection{Block A: Basic characteristics of solar cells}

The laboratory tasks of block A are very important and A1, A2 and A3 had to be carried out by all groups of a given course.

A1: The first laboratory task of block $\mathrm{A}$ is aimed to the measurement of the open circuit voltage, the short circuit current density, the current voltage characteristic, the maximum power point, the fill factor and the series and parallel resistances of solar cells based on single crystalline silicon, polycrystalline silicon, amorphous silicon, CdTe absorber, chalcopyrite absorber as well as of tandem solar cells, triple junction high efficiency solar cells, organic solar cells and dye sensitized solar cells. The measurements are performed with variable load resistances and with a multimeter. The intensity of the sun light is measured independently. Each group gets one or two solar cells for characterization. The solar cells are compared at the lab conference. Table II shows examples of energy conversion efficiencies at AM1.5 (25) and measured by students at $0.67 \mathrm{~kW} / \mathrm{m}^{2}\left(41^{\circ} \mathrm{C}\right.$, Bangkok). Discussions can be stimulated, for example, regarding the influence of the atmosphere on the sun spectrum and therefore on the energy conversion efficiency.

Table II. - Examples for energy conversion efficiencies of three different types of solar cells measured by students and demonstrating the role of smog and temperature (task A1).

\begin{tabular}{|c|c|c|}
\hline Solar cell & $\begin{array}{c}\text { Efficiency } \\
\text { AM1.5, } \\
25^{\circ} \mathrm{C}\end{array}$ & $\begin{array}{c}\text { Efficiency } \\
0.67 \mathrm{~kW} / \mathrm{m}^{2}, \\
41^{\circ} \mathrm{C}, \\
\text { Bangkok, } \\
24.2 .2011\end{array}$ \\
\hline $\begin{array}{c}\text { GaAs based triple } \\
\text { junction for satellites } \\
\text { AZURspace, 2008 }\end{array}$ & $28 \%$ & $14 \%$ \\
\hline $\begin{array}{c}\text { Separately laminated } \\
\text { large single crystalline } \\
\text { Si, BPsolar, 1991 }\end{array}$ & $15 \%$ & $14 \%$ \\
\hline $\begin{array}{c}\text { pin-pin a-Si:H, Schott, } \\
\text { distributed by } \\
\text { CONRAD, 2007 }\end{array}$ & $7 \%$ & $4 \%$ \\
\hline
\end{tabular}

A2: In the second laboratory task of block A the students study the influence of the series and parallel resistances on current voltage characteristics. For this purpose, a crystalline silicon solar cell can be connected with additional external parallel and series resistances (Fig. 1 illustrates the switching board). The current voltage characteristics are measured very fast with a two channel oscilloscope by charging a capacitor. The solar cell is permanently illuminated and can be connected or disconnected from the oscilloscope with a simple switch. The charging of a capacitor gives to the students an idea about the principle of a flasher. Discussions can be related to consequences of increasing series and decreasing parallel resistances for the fill factor, for the short circuit current density and for the open circuit voltage.

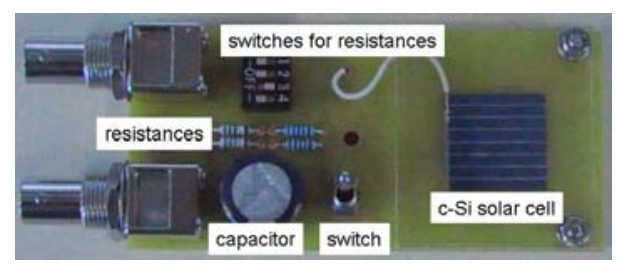

Fig. 1. Switching board (S. Bönisch, Th. Dittrich) for adding series and parallel resistances to a single crystalline silicon solar

cell (area $2 \times 2 \mathrm{~cm}^{2}$ ) and for measuring a current voltage characteristic with a capacitor and a two channel oscilloscope within laboratory task A2. 
A3: The students measure current voltage characteristics of solar cells connected in series and connected in parallel with and without partial shading. The measurements are performed with load resistances. The students have to compare the influence of shaded solar cells in a string with and without a bypass diode. Discussions can be directed to the influence of objects leading to partial shading of modules and solar power plants and to peculiarities of thin film modules.

A4: The students measure the quantum efficiency of unknown solar cells by comparing with a calibrated one. A set of LEDs of different peak wavelengths can be applied instead of using a monochromator. It has to be remarked that measurements with LEDs are less accurate due to the different distribution of light and due to deviations of the real from the nominal peak wavelengths. The students have to discuss sources of errors in the measurement and estimate the short circuit current density at AM1.5 from the quantum efficiency spectrum.

\subsection{Block B: Parameter dependencies of solar cells}

The parameters of solar cells depend on temperature and on light intensity.

B1: In the first laboratory task of block B the students measure the temperature dependence of the open circuit voltage and of the short circuit current density of a crystalline silicon solar cell and of an amorphous silicon solar cell. The students measure the temperature with three different sensors including calibrated resistance (Pt100), a diode (LM35) and an infrared thermometer. The students should consider the accuracy of temperature measurement for each kind of sensor and the homogeneity of temperature distribution across a solar cell. Discussions are directed to the energy production of PV power plants based on different solar cells with respect to a given installed peak power.

B2: The students measure the dependence of the open circuit voltage on the short circuit current density over several orders of magnitude for different types of solar cells (Fig. 2). The students obtain the diode saturation current density, the ideality factor of the diode and the parallel resistance. The discussions are directed towards the comparison of different absorber materials and the role of technologies for the formation of charge-selective contacts.

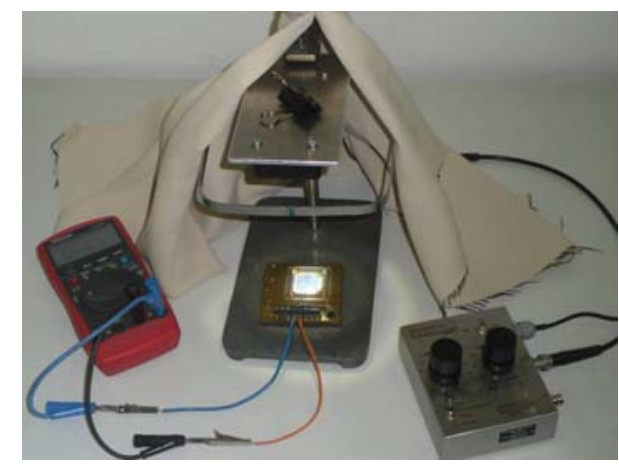

Fig. 2. Example of a setup for the measurement of the dependence of the open circuit voltage on the short circuit current density within laboratory task B2.
B3: The students investigate the intensity dependent energy conversion efficiency of solar cells. The students measure the current voltage characteristics of crystalline and amorphous silicon solar cells at light intensities varying over about two orders of magnitude. The measurements are performed with periodic variable load and a two channel oscilloscope. A field of high power LEDs enables a high homogeneity of illumination. Fig. 3 shows the set-up of the laboratory task. The students plot the normalized energy conversion efficiency as a function of the short circuit current density. The increase of the energy conversion efficiency with increasing light intensity will be demonstrated and limitations due to series and parallel resistances have to be discussed.

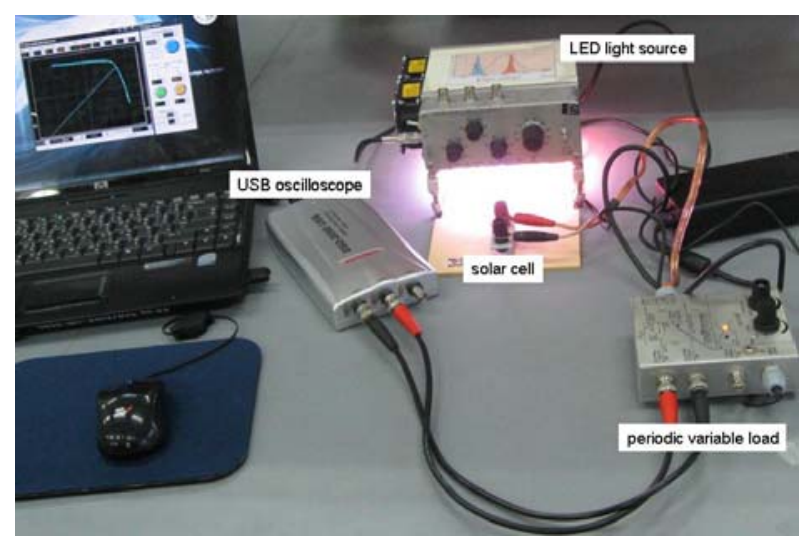

Fig. 3. Setup for the characterization of the normalized intensity dependent energy conversion efficiency within the laboratory task B3 (LED light source for homogeneous illumination over $15 \times 15 \mathrm{~cm}^{2}$ with light intensity up to $150 \mathrm{~mW} / \mathrm{cm}^{2}$ and periodic variable load, developed by M. Franke, EMM).

B4: The temperature dependence of the energy conversion efficiency of a crystalline silicon solar cell is measured in the fourth laboratory task of block B. A highly accurate source measure unit with a constant current source is applied for this investigation. The solar cell is heated slowly and the temperature is measured with a Pt100. The students plot the normalized energy conversion efficiency as a function of temperature and compare this dependence with the temperature dependence of the open circuit voltage. The role of the thermal activation energy of the diode saturation current density related to the thermal activation of the intrinsic carrier concentration and its influence on the open circuit voltage will be discussed.

\subsection{Block C: Aspects of solar cell materials}

The students become familiar with some different measurement methods and solar energy materials during their work on laboratory tasks of block C. The tasks of block $\mathrm{C}$ can be modified depending, for example, on research aspects for a given material. Further, a compact laboratory task related to the measurement of lifetimes in crystalline silicon wafers by free carrier absorption is under preparation.

C1: The capacitance of the pn-junction of a crystalline silicon solar cell is measured with a pulsed light source (LED, duration time of the light pulse of the order of 0.2 
$\mu \mathrm{s})$, a set of load resistances and an oscilloscope. The students obtain the capacitance from the dependence of the $\mathrm{RC}$ time constant on the value of the load resistance. The width of the space charge region is calculated. The doping concentration of the base is found under the assumption of a highly doped emitter. Further the parallel resistance of the solar cell can be obtained and the role of wiring for the accuracy of the measurement will be discussed.

C2: The electroluminescence of single and multi crystalline silicon solar cells is imaged with a camera under different forward current densities. Fig. 4 depicts the set-up for electroluminescence imaging. The influence of grain boundaries, emitter resistance and macroscopic defects will be documented. The students plot the dependence of the electroluminescence signal as a function of the forward current density for different regions of the solar cell and discuss their findings from point of view of injection at low and high levels. The method can be discussed with respect to express in-line quality control of solar cell and module production.

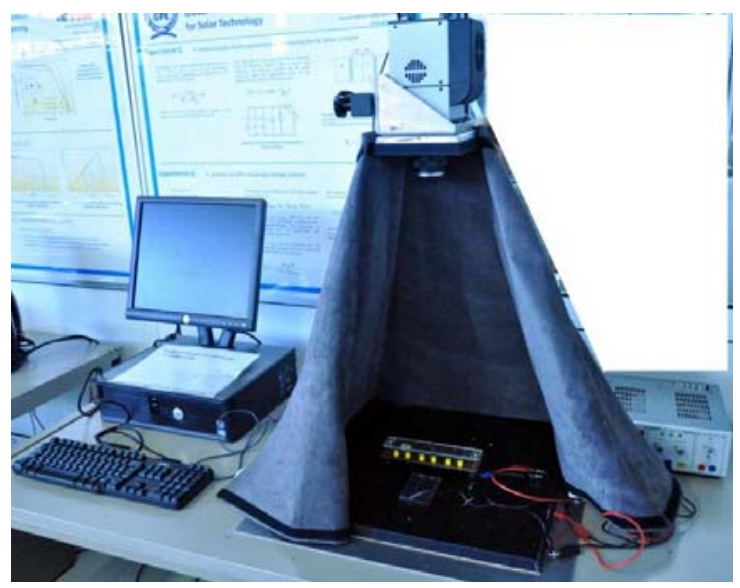

Fig. 4. Setup for electroluminescence imaging of solar cells within laboratory task C2 (installed at GPEsolar).

C3: The students measure surface photovoltage signals in the fixed capacitor arrangement of ultra-thin $\mathrm{In}_{2} \mathrm{~S}_{3}$ or $\mathrm{CdS}$ layers for different thicknesses. Light pulses (duration time about 2 s) are excited with an ultra-bright LED and the intensity is varied over several orders of magnitude. The students get an introduction into the concept of surface photovoltage measurements and a feeling for charge separation across ultra-thin layers with thicknesses of several nm. Results will be discussed within the concept of charging and discharging of surface states. The students will draw consequences of surface states for charge-selective layer systems and solar cells in general.

C4: The molar extinction coefficient of dye molecules and the internal surface area of a very thin nanoporous layer of sintered $\mathrm{TiO}_{2}$ nanoparticles will be obtained in the experiment. For this purpose the students prepare a solution of dye molecules with a certain concentration and measure the transmission at different wavelengths with a prototype of a very compact LED spectrometer. The LEDs of different wavelength are switched on and off one after the other at a given period so that a very rough intensity spectrum can be measured with an oscilloscope (see Fig. 5). The amount of dye molecules adsorbed on the internal surface of nanoporous $\mathrm{TiO}_{2}$ is calculated from the area occupied by one dye molecule and the change of the transmission of the dye solution before and after soaking of the sample. The discussion is directed to adsorption properties of dye molecules and the role of specific binding sites as well as to consequences of a given absorption spectrum for the short circuit current density.

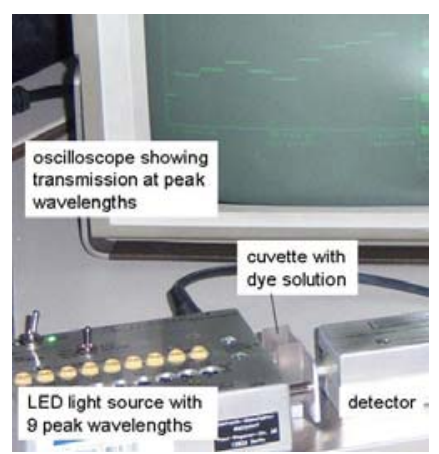

Fig. 5. Components for the measurement of the molar extinction coefficient of dye molecules with modulated LED light source including 9 peak wavelengths (developed by M. Franke, EMM).

\subsection{Block D: Applications of solar energy conversion}

D1: Solar energy can be converted into mechanical work and potential energy by using photovoltaic solar energy conversion and an electro motor with a pump. In this experiment a lead acid battery is charged with a minimodule via a charge controller to store energy and to balance fluctuations of the supply of solar energy. The students measure the total efficiency of a PV powered water pumping system as a function of the pumping height. Fig. 6 shows students measuring the maximum pumping height. The importance and efficiency limitations of energy storage with batteries and water pumping systems will be discussed.

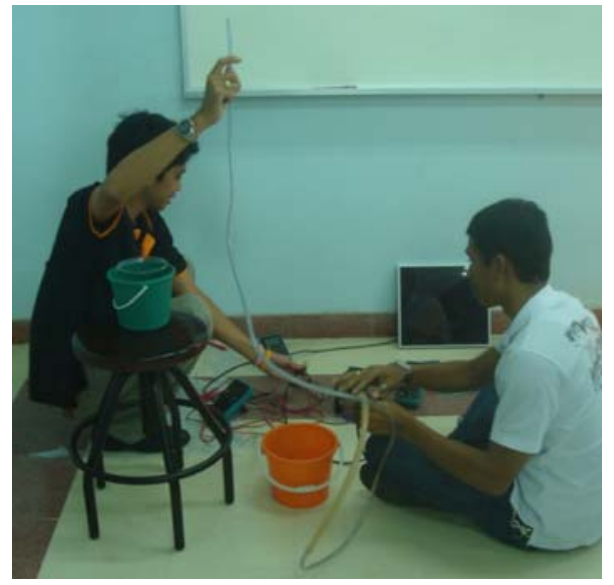

Fig. 6. Students performing laboratory task D1.

D2: Solar energy can be converted into well storable chemical energy by driving electrolytic water splitting. A fuel cell can be used not only for generation of electric power from hydrogen and oxygen but also for water splitting depending on the regime. The students charge the hydrogen and oxygen tanks of a fuel cell car (toy, 
distributed by CONRAD, see Fig. 7) with a mini-module and run the PV powered fuel cell car several times. The energy conversion efficiencies of electrolytic water splitting with catalytic support and the efficiency of the given fuel cell will be measured under operation. Upscaling issues and specific problems of a hydrogen economy will be discussed by the students.

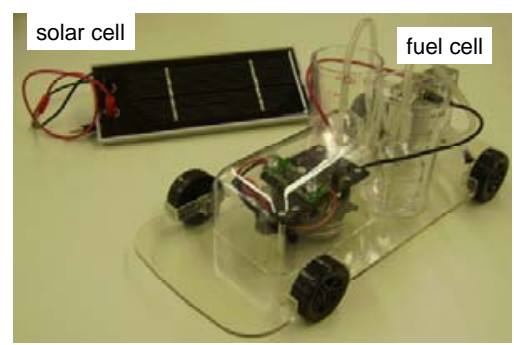

Fig. 7. Mini-module and fuel cell car with fuel cell, hydrogen tank and oxygen tank.

D3: The use of highly energy efficient consumer goods is an important issue for saving energy and for sustainable low cost applications. Ultra-bright LEDs are the most energy efficient devices for illumination. The students charge a battery with a mini-module via a charge controller. A constant current source is connected with the battery and feeds a string of ultra-bright LEDs. Fig. 8 shows a basket filled with the components needed for laboratory task D3. The students are asked to dimension an LED illumination system for a house based on the measured energy conversion efficiencies of the charge controller and of the constant current source and based on the energy consumption of the LEDs. The costs for a respective PV powered LED illumination system can be estimated and compared with the costs in case of using candles.

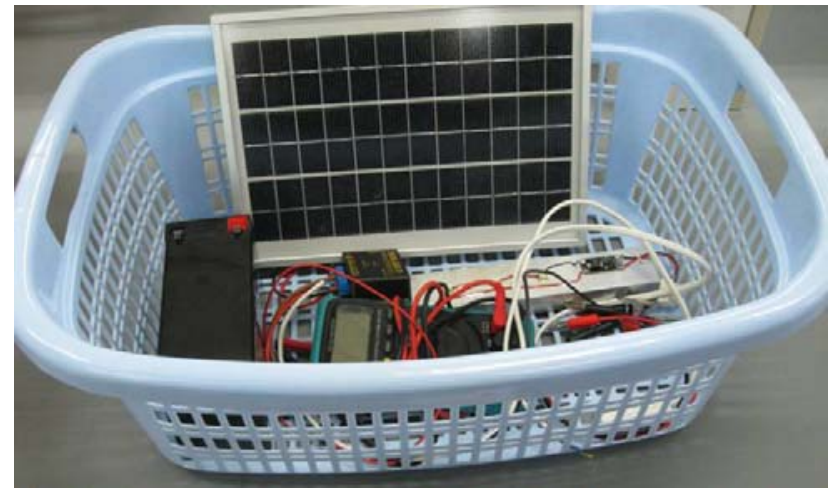

Fig. 8. Components for the characterization of the PV powered LED lighting system within the laboratory task D3 (LEDs: CREE XRE-5).

D4: The energy harvest of PV power plants can be increased if following the sun by tracking. The students characterize a one axis sun tracker with a strong halogen lamp by simulating the position of the sun in a given place at selected times over one year. The experimental error of the given experimental setup should be taken into account. The discussion will be directed to the benefits of one-axis and two-axis sun tracking.

\section{Mobile teaching laboratories}

Teaching of renewable energies demands an interdisciplinary approach which can not be covered by many universities not only in developing countries. However, basic knowledge of solar energy conversion can be easily transferred during well defined compact block courses. For this purpose mobile docents give lectures and use mobile teaching laboratories. In the case of the author, he traveled together with the main components of most of the laboratory tasks described briefly before to the inviting Kasetsart University while standard equipment and laboratory space were provided by the faculty (see also the scheme in figure 9) and faculty members assisted together with advanced students of previous intakes in the laboratory during the course. The support by the inviting university was really a great experience for the author.

The author strongly beliefs that many enthusiastic docents and advanced students would be ready to travel from university to university, for example, in well equipped solar trucks, and stay for a certain time at safe university campuses to teach about solar energy conversion. May be that this will become an option for teaching in Africa. Related projects can be developed in cooperation with governmental organizations and NGOs.

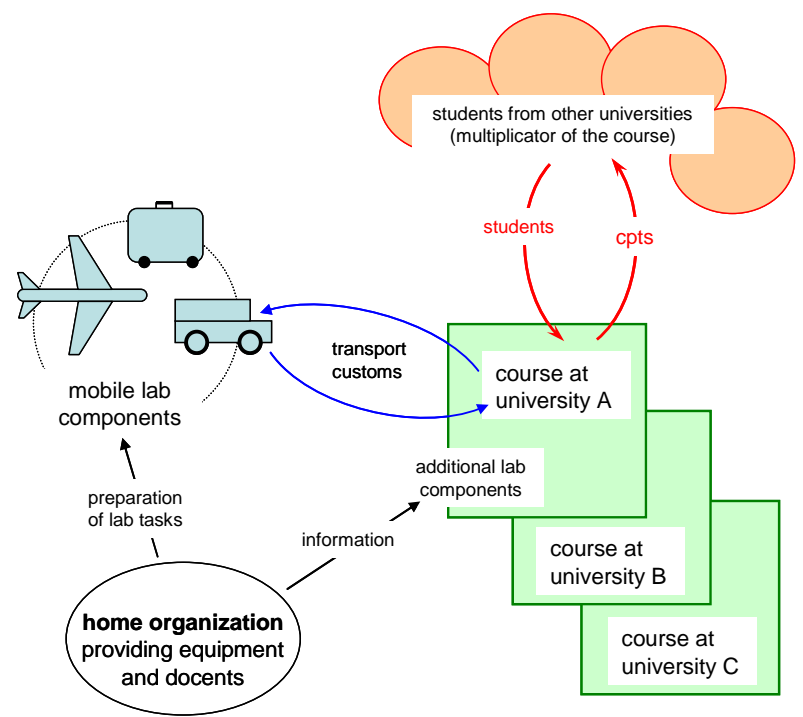

Fig. 9. Schematic of the organization of courses with a mobile teaching laboratory.

\section{Vision of Interdisciplinary Teaching Centres for Renewable Energy}

Many universities in the world have interdisciplinary research centers. Why not yet Interdisciplinary Teaching Centers for Renewable Energy (figure 10) ? Imagine, students from different faculties will meet and carry out experiments together to learn about solar energy conversion in a central place at the university. These students will have better chances to understand each other when creating the future. The laboratory tasks drawn above can serve as a starting point for units from which 
students of different faculties can design their own lab course in solar energy conversion. Of course, for an Interdisciplinary Teaching Center for Renewable Energy the laboratory tasks drawn above have to be completed since they cover only a relatively narrow part in the spectrum of solar cells and solar energy conversion. Laboratory tasks related to light trapping and to luminescence concentrators are under preparation. Important areas such as power quality, system components, wind energy, ... are still missing. Specific aspects of renewable energies for architecture are challenging as well for teaching laboratories. It will be also useful to include tasks related to simulations, for example, of expected power generation when planning PV power plants or of sizing off-grid PV systems. The vision is to have about $30 \ldots 40$ laboratory tasks in an Interdisciplinary Teaching Center for Renewable Energy. Students successfully performing laboratories get credit points (cpts) which are recognized at the home faculties. Depending on the home faculty laboratory tasks from different categories should be combined and specific questions can be added for getting a certain amount of cpts. One advantage of Interdisciplinary Teaching Centers for Renewable Energy is, in comparison to mobile teaching laboratories, that more complex equipment and experiments can be involved.

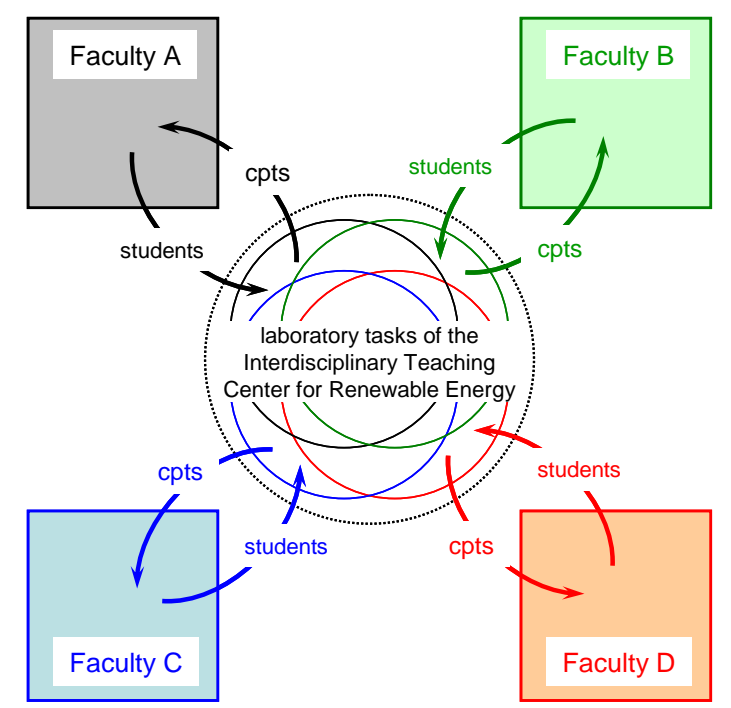

Fig. 10. Schematic of the function of an Interdisciplinary Teaching Center for Renewable Energy within a University.

\section{Conclusions}

Tasks of a complex and flexible teaching laboratory in the area of photovoltaic solar energy conversion have been developed and tested during courses at which participated more than 150 students, young scientists and lecturers during the last five years. The laboratory is complex because it covers basic characteristics of solar cells, dependencies of solar cell parameters on light intensity and temperature, a variety of characterization methods and principles as well as aspects of energy conversion and storage. Some non-conventional low-cost solutions have been included. The laboratory is flexible because it is open for new impacts and improvements and because most of the laboratory tasks can be easily reproduced and realized. Components of the laboratory can be simply implemented into other teaching activities and workshops. For example, parts of the laboratory tasks were applied during an international workshop on photovoltaics in Nairobi (Kenya) in 2007, during a stay of the author as a guest lecturer at the Universidad del Norte (Barranquilla, Colombia) in 2008 and regularly during the International Summer University on Renewable Energy (ISUenergy) in Falera (Switzerland) which started in 2009. The next course in Thailand using the mobile laboratory and implementing laboratory tasks from local universities will be in August 2012 [1].

Students are enthusiastic for performing experiments by themselves. The working atmosphere was always very productive during the laboratory work. The optimum number of group members is two-three for one laboratory task. The laboratory tasks A1, A2, A3 and B2 can serve as buffers when the exact number of participants of a course is not well known before since these tasks can be easily doubled or quadrupled.

It makes sense to implement related laboratories into an interdisciplinary teaching process in the field of renewable energy involving students in science, engineering, civil engineering, teaching and other social sciences. Criteria for credit points can be determined with respect to specific demands at different faculties. The creation of Interdisciplinary Teaching Centers for Renewable Energy will strongly enhance the opportunities for education of students in a decisive area.

\section{Acknowledgement}

The author is grateful to Prof. S. Patharakorn, the Dean of the Faculty of Sciences of the Kasetsart University, to Prof. A. Worayingyong and to Prof. M. Arunchaya, for inviting, stimulation and logistic and financial support during the courses in Bangkok. Further the author is grateful to Prof. G. Seliger, the initiator and head of GPE at the Technical University Berlin, for giving the opportunity to teach students in an international master course. The author thanks Prof. M. Lux-Steiner, the Head of the Institute of Heterogeneous Materials of the Helmholtz Centre Berlin for Materials and Energy, for welcoming the teaching activities of the author. The author is grateful to Prof. S. Bönisch for fruitful cooperation during the development of some laboratory tasks and for developing the laboratory task D4, to Dr. M. Franke for stimulating discussions and for the development and realization of dedicated electronic components and to J. Beckmann for developing a sophisticated LED light source for quantum efficiency measurements. A. Gallego (RENAC) is acknowledged for assistance during the course at the Kasetsart University in 2011. Last but not least, the author is very grateful to his wife and family.

\section{References}

[1] http://www.slri.or.th/ASCM2012/. 